\section{Quantification of allospecific and nonspecific corneal endothelial cell damage after corneal transplantation}

Schepens Eye Research Institute and Massachusetts Eye and Ear Infirmary, Department of Ophthalmology, Harvard Medical School, Boston, MA, USA

Correspondence:

SK Chauhan, Schepens Eye Research Institute and Massachusetts Eye and Ear Infirmary, Department of Ophthalmology, Harvard Medical School, 20 Staniford Street, Boston, MA 02114, USA

Tel: + 1617912 0258;

Fax: + 16179120117

E-mail: sunil_chauhan@

meei.harvard.edu

Received: 17 June 2014 Accepted in revised form: 6 September 2014 Published online: 17 October 2014

\begin{abstract}
Purpose To investigate the effect of host immunity (allospecific) and surgical manipulation (non-allospecific) on corneal endothelial cells (CECs) in corneal transplantation.

Methods Draining lymph nodes and grafted C57BL/6 corneas were harvested from syngeneic recipients, allograft acceptors, and allograft rejectors (BALB/c) 1, 3, and 8 weeks after transplantation. We analyzed CEC apoptosis using an ex vivo cornea-in-the-cup assay, and visualized cell-to-cell junctions using immunohistochemical staining (ZO-1). Automatic cell analysis using Confoscan software was used to measure CEC density as well as changes in CEC morphology by quantifying the coefficient of variation in cell size (polymegethism) and shape (pleomorphism).

Results The cornea-in-the-cup assay showed that allogeneic acceptor $T$ cells and to an even greater extent rejector $T$ cells (but not syngeneic $T$ cells) induced CEC apoptosis. CEC density after corneal transplantation was significantly reduced in allogeneic acceptors compared with syngeneic grafts $(P<0.001)$, and CEC density was even further reduced in the allo-rejector group compared with the allo-acceptor group. Allogeneic grafts showed a greater increase in the coefficient of variation in cell size (polymegethism) when compared with syngeneic grafts 1 week after transplantation $(P=P<0.001)$. However, pleomorphism was not significantly different between syngeneic and allo-acceptor grafts, indicating that
\end{abstract}

SK Chauhan, U Jurkunas, T Funaki, M Dastjerdi and R Dana polymegethism (but not pleomorphism or cell density) is a sensitive indicator of the effect of alloimmunity on CECs.

Conclusions Our data demonstrate that host alloimmunity rather than surgical manipulation alone is the major cause of CEC damage in corneal transplantation, and such morphologic changes of CECs can be detected before the clinically visible onset of allograft rejection.

Eye (2015) 29, 136-144; doi:10.1038/eye.2014.248; published online 17 October 2014

Introduction

Corneal transplantation is the most commonly performed transplantation worldwide. In the United States alone, nearly 40000 cases are performed annually divided between lamellar (partial thickness) cases performed primarily in uninflamed host beds and penetrating (full thickness) cases performed in settings of extensive corneal scarring and/or inflammation. In uninflamed or low-risk host beds, only a minority of grafts suffers from graft rejection. However, corneal transplantation performed on inflamed or high-risk host beds show rejection rates between 50 and $90 \%$ even with maximal local and systemic immune suppression. ${ }^{1-3}$

Despite medical advances, immune rejection of corneal grafts remains the most frequent cause of corneal graft failure. ${ }^{4}$ Several studies have shown that $\mathrm{CD} 4^{+} \mathrm{T}$ cells are the major mediators of acute corneal graft rejection. Corneal endothelial cells (CECs) are the 
principal targets of alloimmunity in corneal transplantation, which primarily involves allospecific $\mathrm{CD}^{+}{ }^{+}$T cells attacking the graft endothelium. ${ }^{4,5}$ The corneal endothelium is a monolayer of neural crestderived cells that line the posterior surface of the cornea. The pump and barrier functions of CECs maintain the corneal transparency. CECs contain numerous sodiumpotassium adenosine triphosphatases $\left(\mathrm{Na}^{+} / \mathrm{K}^{+}\right.$ATPases), which pump fluid out of the stroma to maintain the cornea in a state of relative deturgescence. In addition, tight junctions between the CECs provide a barrier that prevents the influx of fluid from aqueous humor into the stroma. Both of those functions critically depend on sufficient numbers of functional endothelial cells. $^{6-8}$

The human corneal endothelium has a very limited, if any, replicative potential in vivo. ${ }^{9,10}$ When CECs are exposed to stress during inflammation or trauma, cell loss can occur in a focal area that is then repaired by enlargement, sliding, and rearrangement of neighboring cells, but not by mitotic division. ${ }^{8}$ As a result, apoptosis of CECs and morphologic changes in the endothelial cell mosaic have been observed. Morphologic changes of CECs include increased variation in cell size (polymegethism) and in cell shape (pleomorphism). ${ }^{11-14}$ Both polymegethism and pleomorphism are wellestablished parameters that are used to measure endothelial cell function and CEC responses to endogenous as well as exogenous stimuli. ${ }^{11}$

Inflammation after corneal transplantation leads to increased apoptosis of the corneal endothelium, and loss of CECs during graft rejection has been observed in both rodent and human corneal transplants. ${ }^{15-17}$ Although some previous studies have attempted to explain the loss of CECs after transplantation, ${ }^{18,19}$ the quantification of the density and morphologic alterations of CECs has not been investigated. Most notably, it remains unclear to what extent and at what time points CEC loss occurs because of mechanical trauma or/and host immune responses.

In the present study, we quantified allospecific and nonspecific damage to CECs using syngeneic or allogeneic transplants in a well-established mouse model of corneal transplantation. We studied CEC density as well as changes in endothelial cell morphology by quantifying the coefficient of variation in cell size (measure of polymegethism) and the percentage of hexagonal cells (measure of pleomorphism). Our data demonstrate that in addition to surgical trauma, immunity had a key effect on CEC morphology, density, and survival, even before the clinically visible onset of allograft rejection. Thus, these morphologic parameters may be used as sensitive indicators of CEC stress in vivo.

\section{Materials and methods}

\section{Animals}

Eight-week-old Balb/c (H-2d) and C57BL/6 (H-2b) male mice were purchased from Taconic Farms (Germantown, NY, USA) and used as recipients and donors, respectively. Animals were housed in a pathogen-free environment at the Schepens Eye Research Institute animal facility and the study was approved by the Institutional Animal Care and Use Committee. The mice were treated according to the Association for Research in Vision and Ophthalmology Statement for the Use of Animals in Ophthalmic and Vision Research.

\section{Corneal transplantation}

Standard protocol for murine orthotopic corneal transplantation was used, as described previously. ${ }^{18-20}$ Briefly, donor center corneas (2-mm diameter) were excised from C57BL/ 6 mice and sutured on recipient graft beds that had been prepared by excising a $1.5 \mathrm{~mm}$ site from the central cornea of Balb/c mice.

Simultaneously, some Balb/c and C57BL/6 mice received syngeneic grafts to study non-allospecific effects of surgery on CECs. The corneal sutures were removed 7 days after surgery. All grafts were evaluated using slit-lamp biomicroscopy at weekly intervals for up to 8 weeks. Grafts were defined as rejected when they became opaque and iris details could not be recognized clearly. A standardized opacity-grading scheme (ranges from 0 to 5) was used.

\section{Cornea-in-the-cup assay}

To examine apoptosis of CECs induced by allospecific T cells ex vivo, naive C57BL/6 (graft donor) corneal cups were incubated ex vivo with allogeneic $\mathrm{CD}^{+}$or $\mathrm{CD}^{+}{ }^{+} \mathrm{T}$ cells (Balb/c, graft recipients) isolated from the draining lymph nodes of syngeneically grafted recipients, allograft acceptors, or allograft rejectors 3 weeks after transplantation. $\mathrm{CD}^{+}$or $\mathrm{CD} 4{ }^{+} \mathrm{T}$ cells were purified from the draining lymph nodes using magnetic cell sorting and separation (Miltenyi Biotec, Auburn, CA, USA). Purified $\mathrm{CD}^{+}$or $\mathrm{CD}^{+}{ }^{+} \mathrm{T}$ cells were suspended in RPMI-1640 (Life Technologies, Grand Island, NY, USA). The naive C57BL/ 6 corneal cups were incubated with $2 \times 10^{5} \mathrm{CD}^{+}$or $\mathrm{CD}^{+}$T cells for $48 \mathrm{~h}$ in $5 \% \mathrm{CO}_{2}$ at $37^{\circ} \mathrm{C}$, and then washed two times with PBS. To investigate whether allospecific CD4 ${ }^{+} \mathrm{T}$ cells induce apoptosis of CECs in a contact-independent manner, the same experimental approach was performed using 24-well plates with $1-\mu \mathrm{m}$ pore size transwell cell culture inserts (BD Biosciences, Franklin Lakes, NJ, USA). 


\section{Immunohistochemistry}

Corneas from the corneal cup assay and freshly isolated corneas were fixed in absolute ethanol for 20 min in 96-well plates at room temperature (RT). To analyze cell density, corneas were stained with a rabbit ZO-1 antibody $(1: 200$; Life Technologies Zymed, Grand Island, NY, USA) overnight at $4{ }^{\circ} \mathrm{C}$. The cells were then washed and incubated with a donkey FITC-conjugated anti-rabbit antibody (1:200; Santa Cruz Biotechnology, Santa Cruz, CA, USA), and finally permeabilized with $0.1 \%$ Triton X-100 in $0.1 \%$ sodium citrate for $10 \mathrm{~min}$ at RT. TUNEL staining was performed using the In Situ Cell Death Detection Kit TexRed (Roche Diagnostics, Basel, Switzerland) according to the manufacturer's protocol. Three individual areas at the center of the graft and recipient beds were evaluated using confocal microscopy ( $\times 40$ magnification; Leica TCS-SP2, Leica, Wetzlar, Germany).

\section{Analysis of CECs}

Images of corneal endothelium after staining with antiZO-1 were uploaded to the Confoscan4 software (NIDEK Co. Ltd, Fremont, CA, USA), which performs automatic cell analysis. The software was used to detect the number of cell sides, the area of each cell, endothelial cell density, and to calculate polymegethism and pleomorphism. Pleomorphism was quantified as the percentage of hexagonal cells.

\section{Statistical analysis}

Experiments containing greater than two groups were analyzed via two-way ANOVA test with post hoc Bonferroni's multiple comparison test. Comparisons between two groups were analyzed using the Student's T-test. Error bars present standard deviation, and a $P$-value of $<0.05$ was considered statistically significant. All statistical calculations were performed using Prism Version 5.04 software (GraphPad, La Jolla, CA, USA).

\section{Results}

\section{Contribution of alloimmunity to CEC apoptosis}

We first investigated whether alloimmunity or nonspecific inflammatory responses have the primary role in endothelial cell damage in corneal transplantation. Therefore, we used an ex vivo cornea-inthe-cup assay, in which allogeneic corneal buttons (C57BL/6) were incubated with T cells (Balb/c) isolated from syngeneically grafted recipients (syngeneic), allograft-accepted recipients (acceptor), or allograftrejected recipients (rejector). Corneas were stained with an anti-ZO-1 antibody and TUNEL staining was used to determine cell density and apoptosis, respectively. As shown in representative confocal micrographs (Figure 1a), syngeneic CD3 ${ }^{+} \mathrm{T}$ cells did not induce apoptosis of CECs. However, CEC apoptosis was observed after exposure to allogeneic acceptor and rejector $\mathrm{CD}^{+} \mathrm{T}$ cells and the magnitude of CEC apoptosis was even greater after exposure to the rejector $\mathrm{CD}^{+}{ }^{+} \mathrm{T}$ cells.

We next investigated whether $\mathrm{CD} 4{ }^{+} \mathrm{T}$ cells, a major subset of $\mathrm{CD}^{+} \mathrm{T}$ cells involved in the effector response in transplantation, can induce CEC apoptosis and whether these allo-primed $\mathrm{CD}^{+}{ }^{+} \mathrm{T}$ cells induce CEC apoptosis either in a cell-to-cell contact-dependent (direct) or -independent (indirect, cytokine mediated) manner. CEC apoptosis was only seen in CECs exposed to allogeneic but not syngeneic CD4 T cells, and rejector CD4 T cells induced significantly more apoptosis than acceptor CD4 T cells both directly $(P=0.0002)$ and indirectly $(P=0.004)$ (Figures $1 \mathrm{~b}$ and $\mathrm{c}$ ). Based on these findings, we hypothesize that allo-primed $\mathrm{CD}^{+}{ }^{+} \mathrm{T}$ cells are the major T-cell subset that induces CEC apoptosis primarily by the secretion of apoptosis-inducing cytokines/molecules.

\section{CEC loss after transplantation}

We investigated whether alloimmunity affects the destruction of the endothelial cell monolayer by analyzing CEC density in corneal grafts (Figure 2) and host beds (Figure 3 ) of syngeneically grafted recipients, allograft acceptors, and allograft rejectors. Endothelial cell-to-cell junctions were visualized with an anti-ZO-1 antibody. At selected time points, corneas were harvested and examined by confocal microscopy to detect and count CECs. Automatic cell analysis was carried out using Confoscan software. CEC density in corneal transplants was compared with non-transplanted controls. In corneal grafts (Figure 2), we observed a significant decrease $(\sim 20 \%, P<0.001)$ in CEC density 1 week after transplantation in syngeneic ( $2347 \pm 78$ cells $/ \mathrm{mm}^{2}$ ) compared with non-transplanted control corneas $\left(2821 \pm 36\right.$ cells $\left./ \mathrm{mm}^{2}\right)$. We did not detect a statistically significant difference in CEC density between syngeneic $\left(2347 \pm 78\right.$ cells $\left./ \mathrm{mm}^{2}\right)$ and allogeneic $\left(2161 \pm 79\right.$ cells $\left./ \mathrm{mm}^{2}\right)$ grafts at that time point. In syngeneic grafts, we found a continued gradual decrease in CEC density 3 and 8 weeks after transplantation compared with controls. Compared with syngeneic grafts, allo-acceptors displayed an even greater decline in CEC density to $1632 \pm 141$ cells $/ \mathrm{mm}^{2}(P<0.001) 3$ weeks and $1494 \pm 134$ cells $/ \mathrm{mm}^{2}(P<0.001) 8$ weeks after transplantation. In allo-rejector grafts, there was a significant decrease in CEC density 3 weeks after transplantation compared with allo-acceptor grafts 
a

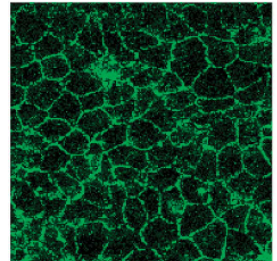

Sygeneic CD3 T cell

b
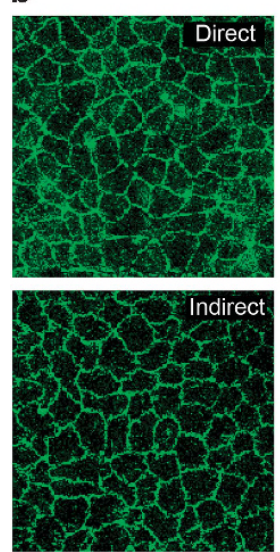

Sygeneic CD4 T cell

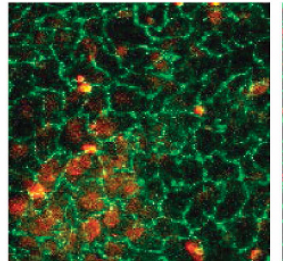

Acceptor CD3 T cell
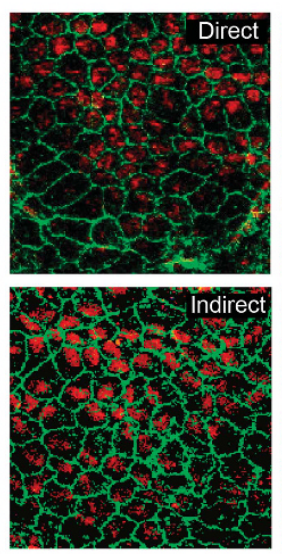

Acceptor CD4 T cell

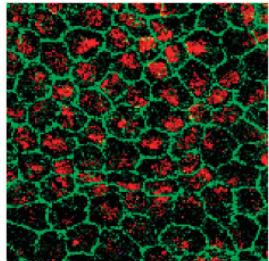

Rejector CD3 T cell
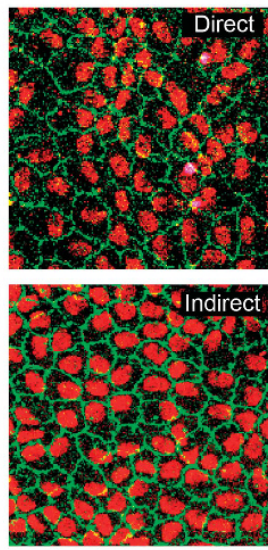

Rejector CD4 T cell

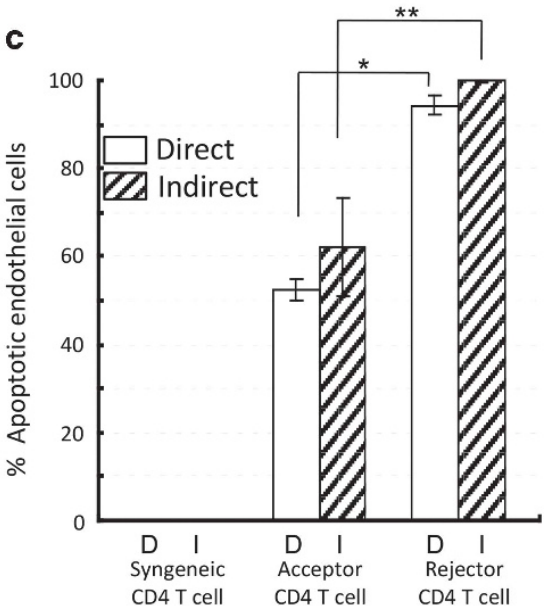

Figure 1 Effect of alloimmunity on CECs. (a) Representative confocal micrographs showing naive C57BL/6 (graft donor) corneal cups incubated with allogeneic (Balb/c, graft recipients) $\mathrm{CD}^{+}$T cells isolated from the draining lymph nodes of syngeneically grafted recipients, allograft acceptors, or allograft rejectors at week 3 after transplantation. After $48 \mathrm{~h}$ of incubation, corneas were stained for zonula occluden-1 (ZO-1) (green) and terminal deoxynucleotidyl transferase-mediated dUTP nick-end labeling assay (TUNEL) (red) to visualize endothelial cell-to-cell junctions and apoptotic cells, respectively (magnification $\times 40$ ). (b) Representative confocal micrographs showing naive C57BL/6 (graft donor) corneal cups incubated directly or indirectly (using transwells of 1- $\mu \mathrm{m}$ pore size) with $\mathrm{CD}^{+}{ }^{+} \mathrm{T}$ cells isolated from the draining lymph nodes of syngeneically grafted recipients, allograft acceptors, or allograft rejectors at week 3 after transplantation. CD4 ${ }^{+} \mathrm{T}$ cells induced apoptosis of CECs in a contact-dependent (direct; upper panel) or contactindependent (indirect; lower panel) manner. (c) Bar diagram showing the percentages of apoptotic (TUNEL-positive) CECs in a contact-dependent (direct) or contact-independent (indirect) manner incubated ex vivo with allogeneic CD4 ${ }^{+} \mathrm{T}$ cells of the different graft recipient groups. Data are presented as mean \pm SEM. $\left({ }^{*} P=0.0002 ;{ }^{* *} P=0.004\right)$. Each group consists of $n=6$ mice and data from one out of three independent experiments is shown.

$\left(862 \pm 104\right.$ cells $\left./ \mathrm{mm}^{2}, P<0.001\right)$ and CEC density was uncountable 8 weeks after transplantation because of complete loss of endothelial cell mosaic (Figure 2b). These results demonstrate that CEC loss is significantly greater in allogeneic grafts than in syngeneic grafts, and such loss is even greater in the allo-rejector group.

Next, we analyzed CEC density in host beds (Figure 3) and found no significant differences among syngeneic, acceptor, and rejector transplant groups. Interestingly, we observed a significant decrease in CEC density in the host beds of all transplanted groups compared with the nontransplanted group 8 weeks after transplantation $(P<0.001)$.

\section{CEC polymegethism after transplantation}

To evaluate the variation in size of CECs after transplantation, we determined the coefficient of variation in cell size (polymegethism) in both grafts and host beds
(Figure 4). In non-transplanted controls, polymegethism remained consistently at baseline levels for up to 8 weeks ( $<0.2$ coefficient of variation). Syngeneic grafts displayed a gradual increase in the coefficient of variation in cell size compared with controls. Allogeneic grafts showed a significant increase in polymegethism compared with syngeneic grafts at weeks 1 and 3 . At week 3 after transplantation, rejector grafts showed a maximum variation of $0.7 \pm 0.1$ and thereafter CECs were undetectable (Figure 4b). In host beds, no significant change of the coefficient of variation in cell size was observed between control and transplant recipient groups for up to 8 weeks after transplantation (Figure 4c).

\section{CEC pleomorphism after transplantation}

Normally, CECs exhibit a hexagonal shape that allows optimization of energy balance of these highly 
a
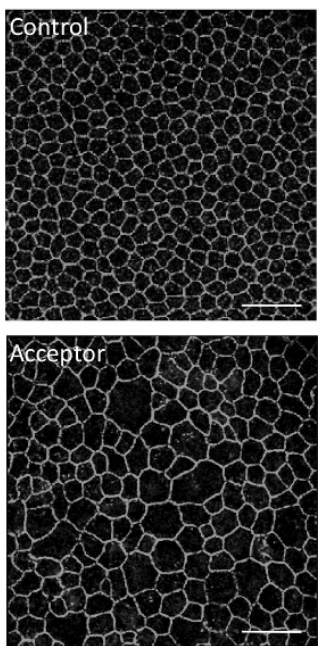

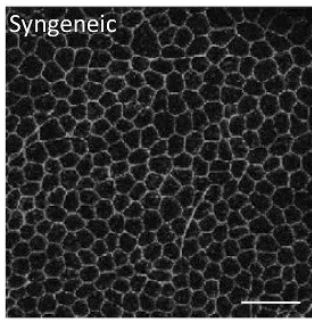

Rejector

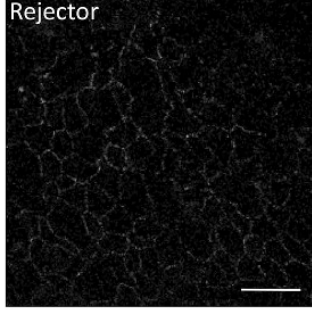

b

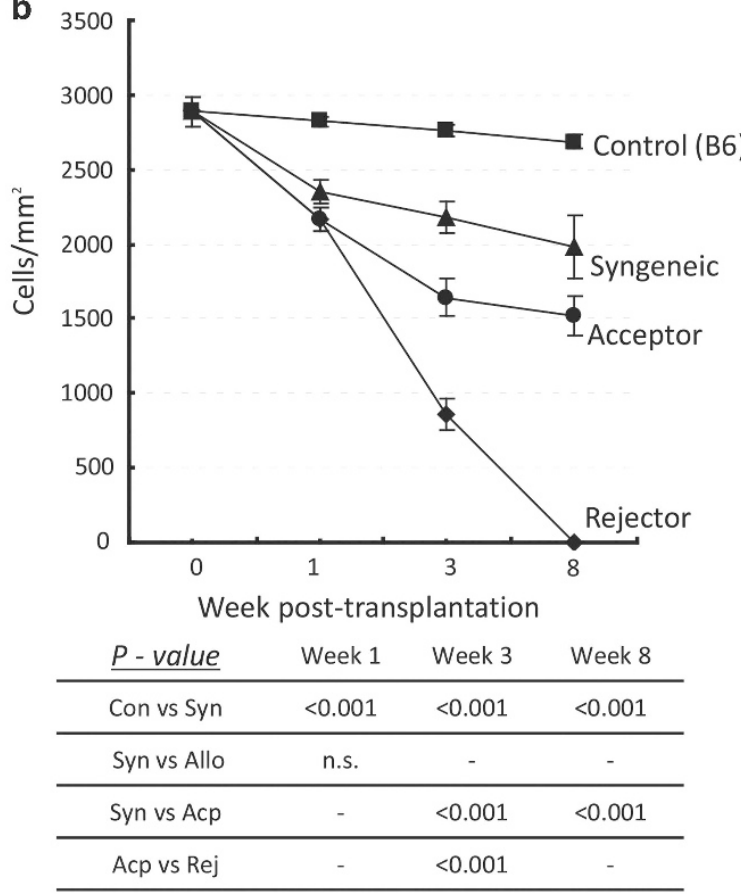

Figure 2 CEC loss in donor grafts after transplantation. (a) Representative confocal micrographs of corneal grafts isolated from syngeneically grafted recipients, allograft acceptors, and allograft rejectors at week 3 after transplantation. To visualize CEC cell-to-cell junctions, corneas were stained with zonula occluden-1 (ZO-1) (green). CEC densities in the normal corneas of age- and sex-matched naive mice are shown as controls. The scale bars are equal to $75 \mu \mathrm{m}$ (magnification $\times 40$ ). (b) CEC density in donor grafts isolated from different transplant groups and a non-transplant (control) group at day 0, week 1, week 3, and week 8 after transplantation. Data are presented as mean \pm SEM. Comparisons of $P$-values in control (Con) vs syngeneic grafts (Syn), syngeneic vs allogeneic grafts (Allo), syngeneic $v s$ allo-accepted grafts (Acp), and allo-accepted $v s$ allo-rejected grafts (Rej) are shown in the table, and $P<0.05$ is considered significant. Each group consists of $n=6$ mice and data from one out of three independent experiments is shown. A full color version of this figure is available at the Eye journal online.

a
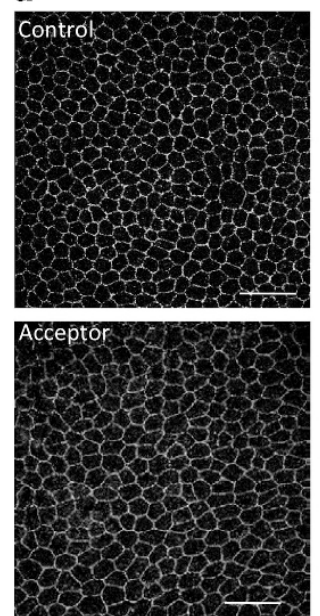

b

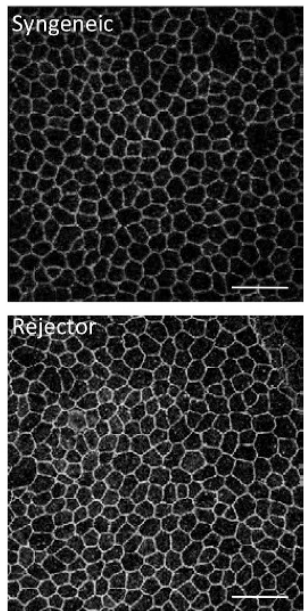

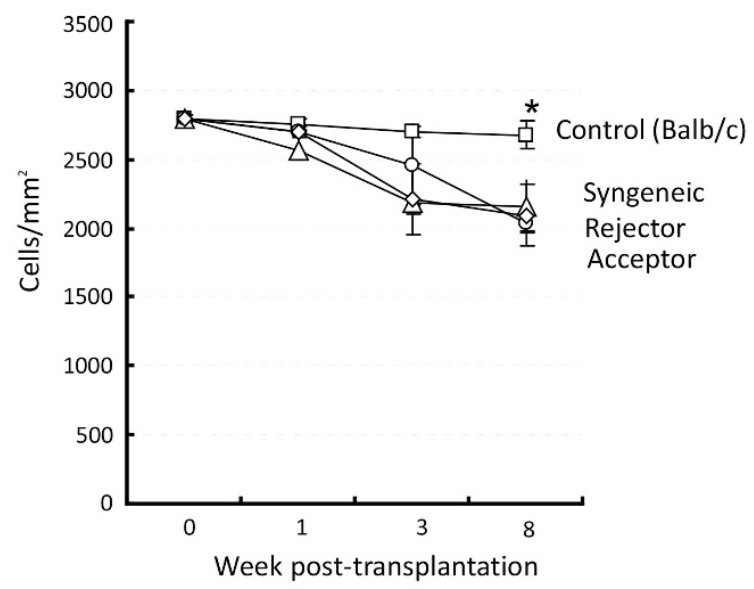

Figure 3 CEC loss in host beds after transplantation. (a) Representative confocal micrographs of host beds isolated from syngeneically grafted recipients, allograft acceptors, and allograft rejectors at week 3 after transplantation. To visualize endothelial cell-to-cell junctions, corneas were stained with zonula occluden-1 (ZO-1) (green). CEC densities in the normal corneas of age- and sex-matched naive mice are shown as controls. The scale bars are equal to $75 \mu \mathrm{m}$ (magnification $\times 40$ ). (b) CEC density in host beds isolated from the different transplant groups and a non-transplant (control) group at day 0, week 1, week 3, and week 8 after transplantation. Each group consists of $n=6$ mice and data from one out of three independent experiments is shown. A full color version of this figure is available at the Eye journal online. 
a

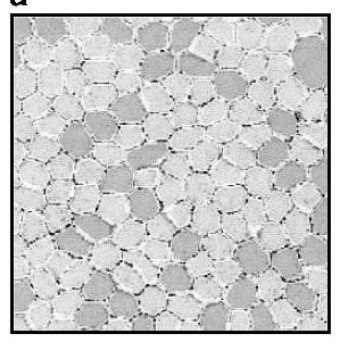

b

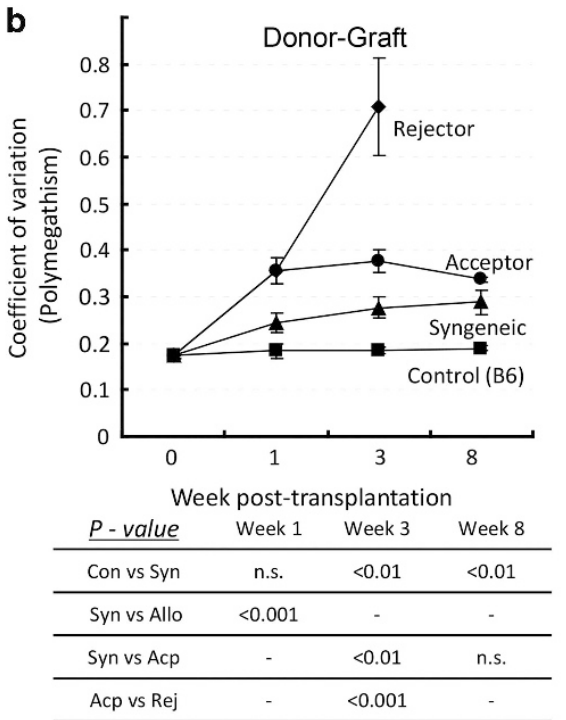

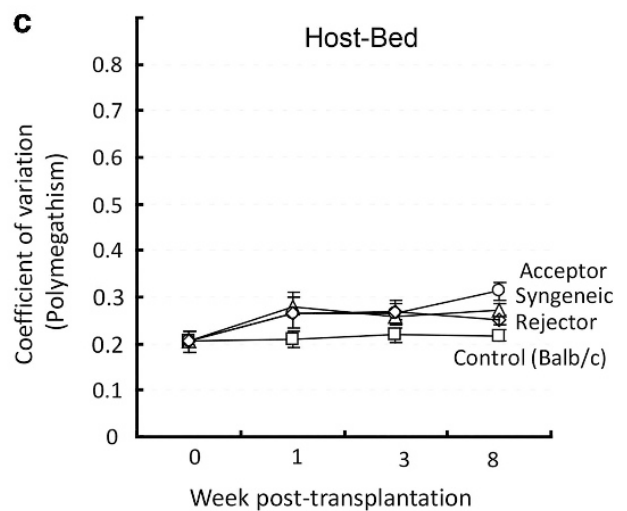

Figure 4 Polymegethism in CECs after transplantation. Cornea from syngeneically grafted recipients, allograft acceptors, allograft rejectors, and non-transplanted mice (control) were harvested at different time points after transplantation. Confocal micrographs of zonula occluden-1 (ZO-1)-stained CECs were analyzed by Confoscan4 software (NIDEK Co. Ltd) to study the polymegethism of CECs. (a) Representative colored micrograph showing CECs of an allograft rejector recipient 3 weeks after transplantation showing polymegethism (cells with large and abnormal size are shown in red color). (b) Cumulative data of the coefficient of variation in morphology of CECs presented as line graphs showing CEC polymegethism in donor graft areas of syngeneically grafted recipients, allograft acceptors, allograft rejectors, and of control mice (C57B16) at day 0, week 1, week 3, and week 8 after transplantation. Comparisons of $P$-values in control (Con) vs syngeneic grafts (Syn), syngeneic vs allogeneic grafts (Allo), syngeneic vs acceptor grafts (Acp), and acceptor vs rejector grafts (Rej) are shown in the table, and $P<0.05$ is considered significant. (c) Cumulative data presented as line graphs showing polymegethism of CECs in host bed areas of the different corneal graft recipients and controls (Balb/c) at day 0 , week 1 , week 3 , and week 8 after transplantation. Each group consists of $n=6$ mice and data from one out of three independent experiments is shown. A full color version of this figure is available at the Eye journal online.

metabolically active cells. ${ }^{11}$ Loss of hexagonality is a measure of endothelial cell distress and is represented by the calculation of cell shape variation, termed as pleomorphism. We determined pleomorphism or loss of cell hexagonality in the grafts and host beds (Figure 5). In grafts, syngeneic transplants showed a significant reduction in the percentage of hexagonal cells compared with CECs in the non-transplanted control corneas $(59.0 \% \pm 0.5)$. At weeks 1 and 8 , we observed no significant difference in CEC pleomorphism between syngeneic and allo-acceptor grafts. However, allo-rejector grafts showed a maximum reduction in hexagonal CECs $(25.3 \% \pm 3.6$, $P=0.01) 3$ weeks after transplantation compared with alloacceptor (43.6 \pm 5.6$)$ grafts (Figure $5 b)$. In host beds (Figure 5c), a small but not significant reduction was observed among syngeneic, allo-acceptor, and allo-rejector host beds. Although we observed a small reduction of hexagonal CECs in all transplant groups compared with non-transplant controls (syngeneic: $45.8 \pm 4.9$; alloacceptor: $43.5 \pm 2.5$; allo-rejector: $45.8 \pm 3.9$ ).

\section{Discussion}

The present study was designed to investigate the comparative effect of host immune response (allospecific) and surgical manipulation (nonspecific) on CEC damage in a mouse model of corneal transplantation. We here show that host alloimmunity, which is primarily mediated by $\mathrm{CD}^{+} \mathrm{T}$ cells, is the principal cause of progressive loss of CECs in corneal transplantation. Moreover, our data demonstrate that in addition to surgical trauma, alloimmunity has a key effect on CEC morphology and survival, even before a clinically visible onset of allograft rejection.

T-cell-mediated alloimmunity has been shown as the main cause of immune rejection of corneal grafts. ${ }^{21-23}$ Corroborating previous studies, ${ }^{4,5}$ our data confirm that allospecific $\mathrm{CD} 4{ }^{+} \mathrm{T}$ cells are the major T-cell subset that induces CEC apoptosis. Interestingly, these allospecific $\mathrm{CD}^{+}{ }^{+} \mathrm{T}$ cells do not require direct cell-to-cell contact to exert their damaging effects on CECs. CEC apoptosis mediated by $\mathrm{CD} 4{ }^{+} \mathrm{T}$ cells in a non-contact-dependent mechanism could be primarily promoted via secretion of apoptosis-inducing cytokines/molecules. In corneal transplantation, a major subset of $\mathrm{CD} 4^{+} \mathrm{T}$ cells are $\mathrm{T}$ helper type 1 cells, ${ }^{4}$ which are characterized by the expression of their signature cytokine IFN- $\gamma$, and other proinflammatory cytokines such as TNF- $\alpha$ and IL-1. These proinflammatory cytokines (IFN- $\gamma$, TNF- $\alpha$, and IL-1) have been shown to induce apoptosis in CECs. ${ }^{24}$ 
a

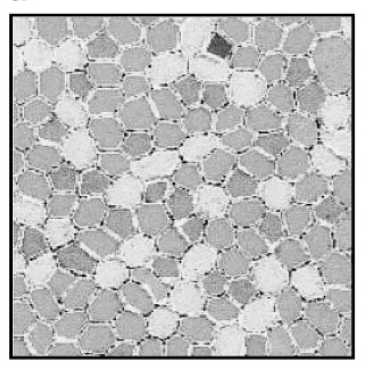

b

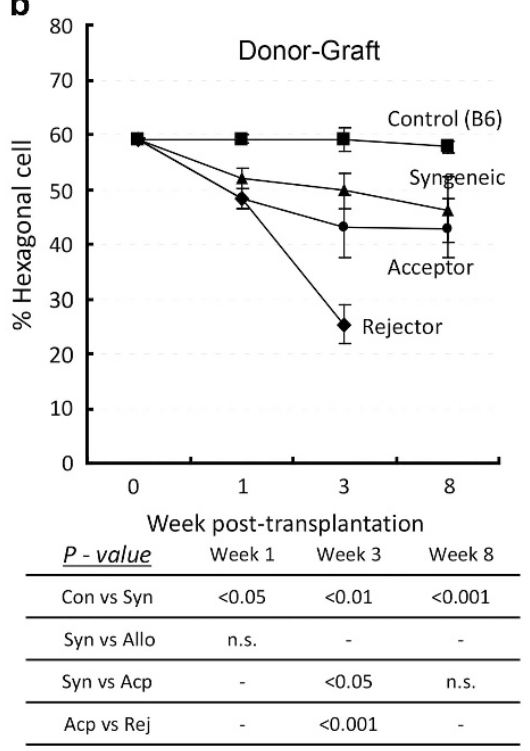

c

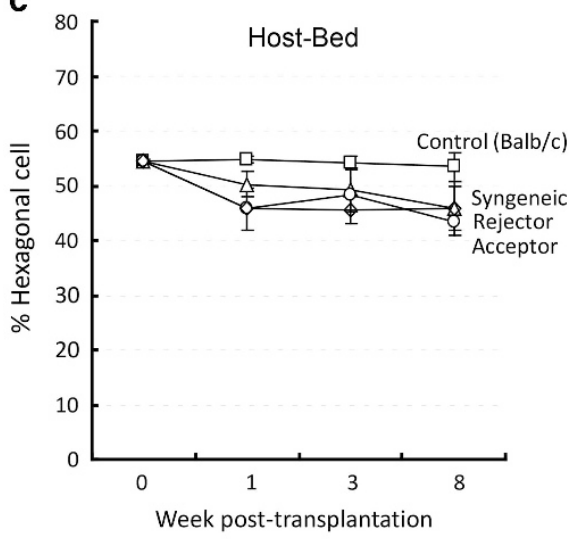

Figure 5 Pleomorphism in CECs after transplantation. Cornea from syngeneically grafted recipients, allograft acceptors, allograft rejectors, and non-transplanted mice (control) were harvested at different time points after transplantation. Confocal micrographs of zonula occluden-1 (ZO-1)-stained CECs were analyzed by Confoscan4 software (NIDEK Co. Ltd) to study CEC pleomorphism (\% of hexagonal cells). (a) Representative colored micrograph showing CECs of an allograft rejector 3 weeks after transplantation showing pleomorphism (normal, hexagonal cells are shown in green). (b) Cumulative data presented as line graphs showing CEC pleomorphism in donor graft areas of syngeneically grafted recipients, allograft acceptors, allograft rejectors, and of control mice (C57Bl6) at day 0, week 1, week 3, and week 8 after transplantation. Comparisons of $P$-values in control (Con) vs syngeneic garfts (Syn), syngeneic vs allogeneic grafts (Allo), syngeneic $v$ s acceptor grafts (Acp), and acceptor $v$ s rejector grafts (Rej) are shown in the table, and $P<0.05$ is considered significant. (c) Cumulative data presented as line graphs showing CEC pleomorphism in host bed areas of different corneal graft recipients and controls (Balb/c) at day 0 , week 1, week 3, and week 8 after transplantation. Each group consists of $n=6$ mice and data from one out of three independent experiments is shown. A full color version of this figure is available at the Eye journal online.

However, it has been shown that rejection not mediated by CD4 T cells can occur as well. ${ }^{25}$

The main parameters of CEC viability are cell density, polymegethism, and pleomorphism. ${ }^{26}$ In this study, the cell density of CECs in the grafts was not significantly reduced in syngenic grafts compared with allografts 1 week after transplantation. Three to eight weeks after transplantation, however, we found a significant difference in cell density between syngenic and allografted transplants. Thus, surgical manipulation damaged CECs 1 week after transplantation; at later time points, both surgical damage and allo-specific immune responses did affect cell density after transplantation. Cell density of host beds was reduced equally in all transplanted mice for all time points, suggesting that CECs from host beds may migrate to the graft to compensate for CEC loss in the graft. Similar results have been observed by Böhringer et $a l^{27}$ in human, where the graft endothelium was replaced by the recipient bed endothelium. Another study reported that endothelial cell loss continued at an accelerated rate for many years both after corneal transplantation and after cataract surgery, which suggest that the continued cell loss may not solely be the result of surgical trauma even in the absence of an allograft. ${ }^{28}$ Quantifying polymegethism and pleomorphism is a more sensitive measurement than cell density measurement alone ${ }^{26}$ as they likely represent early deficiencies in barrier and/or pump function.

Indeed, 1 week after transplantation we found a significant increase in polymegethism comparing syngenic grafts with allografts (including acceptors) and acceptors with rejectors, and our data indicate an effect of allo-immune responses on CEC morphology as early as 1 week after surgery. In contrast, the percentages of hexagonal cells or pleomorphism were not significantly different between syngeneic and allografts (including acceptors) at weeks 1 and 8, but showed a difference when acceptors were compared with rejectors 3 weeks after transplantation. Hence, our morphologic data indicate that polymegethism (but not pleomorphism or cell density) is a sensitive indicator of the effect of alloimmunity on CECs at early time points after transplantation. Interestingly, polymegethism has been shown to define functional deficiency in CECs better than pleomorphism, ${ }^{29}$ and polymegethism is regarded as an early manifestation in contact lens-induced hypoxic stress on corneal endothelium..$^{30}$ Based on these previous findings and our data, we thus suggest that measuring 
polymegethism is a more sensitive method to detect the effect of immunity on CEC viability than pleomorphism.

In summary, the effect of transplantation and alloimmunity on CECs can be detected by morphologic changes indicating an early stress response before loss in cell density, development of edema, and opacification. The variability in cell shape (polymegethism) is a marker for CEC wound healing and may allow quantification of alloimmunity-induced changes even before the clinically visible onset of graft rejection. This more sensitive measure of evaluating CEC viability in transplantation may add to the precision of measuring host alloresponse.

\section{Summary}

\section{What was known before}

- Inflammation after corneal transplantation is the main cause of increased apoptosis of the CECs and loss of CECs during graft rejection.

- Previous studies have demonstrated that CD4+ T cells can inflict damage to allogeneic CECs in vitro.

\section{What this study adds}

- In the present study, we differentially quantified allospecific and nonspecific inflammation-mediated damage to CECs after corneal transplantation.

- Our data show that in addition to surgical trauma (nonspecific inflammation), allospecific immunity had a key damaging effect on CEC morphology, density, and survival, even before the clinically visible onset of allograft rejection.

- Our data suggest that endothelial shape alterations could be a novel and early diagnostic marker in corneal transplantation.

\section{Conflict of interest}

The authors declare no conflict of interest.

\section{Acknowledgements}

We thank Dr Susanne Eiglmeier, PhD, Schepens Eye Research Institute, Boston for assisting in editing and formatting this manuscript. This work was supported by NIH/NEI-EY12963 (to RD).

\section{References}

1 Niederkorn JY. The immune privilege of corneal allografts. Transplantation 1999; 67: 1503-1508.

2 Dana MR, Moyes AL, Gomes JA. The indications for and outcome in pediatric keratoplasty. A multicenter study. Ophthalmology 1995; 102: 1129-1138.

3 CCTS. The Collaborative Corneal Transplantaion Studies Research Group: Effectiveness of histocompatability matching in high risk corneal transplantation. Arch Ophthalmol 1922; 110: 1392-1403.

4 Boisgerault F, Liu Y, Anosova N, Ehrlich E, Dana MR, Benichou G. Role of CD4 + and CD8 + T cells in allorecognition: lessons from corneal transplantation. J Immunol 2001; 167: 1891-1899.

5 Hegde S, Beauregard C, Mayhew E, Niederkorn JY. CD4(+) T-cell-mediated mechanisms of corneal allograft rejection: role of Fas-induced apoptosis. Transplantation 2005; 79(1): 23-31.

6 Mishima S. Corneal thickness. Surv Ophthalmol 1968; 3: $57-96$.

7 Fischbarg J, Lim JJ. Role of cations, anions and carbonic anhydrase in fluid transport across rabbit corneal endothelium. J Physiol 1974; 241: 647-675.

8 Kaufman HE, Capella JA, Robbins JE. The human corneal endothelium. Am J Ophthalmol 1966; 61(5, Part 1): 835-841.

9 Murphy C, Alvarado J, Juster R, Maglio M. Prenatal and postnatal cellularity of the human corneal endothelium: a quantitative histologic study. Invest Ophthalmol Vis Sci 1984; 25: 312-322.

10 Bourne WM, Nelson LR, Hodge DO. Central corneal endothelial cell changes over a ten-year period. Invest Ophthalmol Vis Sci 1997; 38: 779-782.

11 Warning III GO, Bourne WM, Edelhauser HF, Kenyon KR. The corneal endothelium. Normal and pathologic structure and function. Ophthalmology 1982; 89(6): 531-590.

12 Rao GN, Aquavella JV, Goldberg SH, Berk SL. Pseudophakic bullous keratopathy, relationship to preoperative corneal endothelial status. Ophthalmology 1984; 91: 1135-1141.

13 MacRae SM, Matsuda M, Phillips DS. The long-term effects of polymethylmethacrylate contact lens wear on corneal endothelium. Ophthalmology 1994; 101: 365-370.

14 Shultz RO, Matsuda M, Yee RW, Edelhauser HF, Schultz KJ. Corneal endothelial changes in type 1 and type 2 diabetes mellitus. Am J Ophthalmol 1984; 98: 401-410.

15 Musch DC, Schwartz AE, Fitzgerald-Shelton K, Sugar A, Meyer RF. The effect of allograft rejection after penetrating keratoplasty on corneal endothelial cell density. Am J Ophthalmol 1991; 111: 739-742.

16 Barcia RN, Dana R, Kazlauskas A. Corneal graft rejection is accompanied by apoptosis of the endothelium and is prevented by gene therapy with Bcl-xL. Am J Transplant 2007; 7: 2082-2089.

17 Claerhout I, Beele H, Kestelyn P. Graft failure: I. Endothelial cell loss. Int J Ophthalmol 2008; 28(3): 165-173.

18 Hori J, Streilein JW. Dynamics of donor cell persistence and recipient cell replacement in orthotopic corneal allografts in mice. Invest Ophthalmol Vis Sci 2001; 42: 1820-1828.

19 Plskova J, Kuffova L, Filipec M, Holan V, Forrester JV. Quantitative evaluation of the corneal endothelium in the mouse after grafting. Br J Ophthalmol 2004; 88(9): 1209-1216.

20 Chauhan SK, Saban DR, Dohlman TH, Dana R. CCL-21 conditioned regulatory $\mathrm{T}$ cells induce allotolerance through enhanced homing to lymphoid tissue. J Immunol 2014; 192(2): 817-823.

21 Liu Y, Hamrah P, Zhang Q, Taylor AW, Dana MR. Draining lymph nodes of corneal transplant hosts exhibit evidence for donor major histocompatibility complex (MHC) class IIpositive dendritic cells derived from MHC class II-negative grafts. J Exp Med 2002; 195: 259-268.

22 Huq S, Liu Y, Benichou G, Dana MR. Relevance of the direct pathway of sensitization in corneal transplantation is 
dictated by the graft bed microenvironment. J Immunol 2004; 173: 4464-4469.

23 Claerhout I, Kestelyn P, Debacker V, Beele H, Leclercq G. Role of natural killer cells in the rejection process of corneal allografts in rats. Transplantation 2004; 77(5): 676-682.

24 Sagoo P, Chan G, Larkin DF, George AJ. Inflammatory cytokines induce apoptosis of corneal endothelium through nitric oxide. Invest Ophthalmol Vis Sci 2004; 45: 3964-3973.

25 Niederkorn JY, Stevens C, Mellon J, Mayhew E. CD4 + T-cell-independent rejection of corneal allografts. Transplantation 2006; 81: 1171-1178.

26 Yee RW, Geroski DH, Matsuda M, Champeau EJ, Meyer LA, Edelhauser HF. Correlation of corneal endothelial pump site density, barrier function, and morphology in wound repair. Invest Ophthalmol Vis Sci 1985; 26(9): 1191-1201.
27 Böhringer D, Böhringer S, Poxleitner K, Birnbaum F, Schwartzkopff J, Maier P et al. Long-term graft survival in penetrating keratoplasty: the biexponential model of chronic endothelial cell loss revisited. Cornea 2010; 29: 1113-1117.

28 Armitage WJ, Dick AD, Bourne WM. Predicting endothelial cell loss and long-term corneal graft survival. Invest Ophthalmol Vis Sci 2003; 44: 3326-3331.

29 Bourne WM, Shearer DR. Effects of long-term rigid contact lens wear on the endothelium of corneal transplants for keratoconus 10 years after penetrating keratoplasty. CLAO J 1995; 21(4): 265-267.

30 Stocker EG, Schoessler JP. Corneal endothelial polymegethism induced by PMMA contact lens wear. Invest Ophthalmol Vis Sci 1985; 26(6): 857-863. 